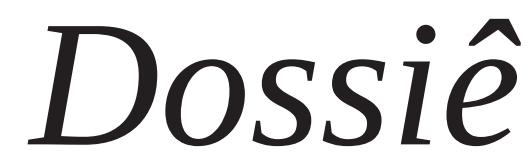

Ler e ler literatura: enfrentamentos 



\title{
Literatura na escola: priorizando a velhice... ${ }^{1}$
}

\section{Literature at school: prioritizing old age...}

\author{
Flávia Brocchetto Ramos * \\ Universidade de Caxias do Sul \\ Letícia da Rocha** \\ Universidade de Caxias do Sul
}

Resumo: A produção de livros infantis ganha cada vez mais espaço no mercado editorial, explicitando desafios e possibilidades de construção da infância na contemporaneidade. Desse modo, temas antes silenciados pelo gênero, como a velhice, por exemplo, passam a ser inseridos nas obras literárias destinadas à infância. Este artigo investiga como a velhice e a infância dialogam a partir do modo como personagens idosos e infantis se relacionam. Para tanto, De carta em carta, de Ana Maria Machado (2009), e Guilherme Augusto Araújo Fernandes, de Men Fox (1995), pertencentes ao acervo dos anos iniciais do Ensino Fundamental do PNBE 2010, são analisados a partir do modo como representam a velhice. A investigação pauta-se em princípios de descrição e análise do enredo das obras, construído por meio da linguagem verbal e visual, tendo por pressupostos D’Onófrio (2004) e Dondis (2007), que pesquisam, respectivamente, a narrativa e a visualidade. Assim, foi possível perceber que o tema escolhido, nos títulos analisados, retrata problemas sociais vividos pelo idoso na contemporaneidade, tais como o abandono em asilos e as dificuldades burocráticas enfrentadas para usufruir de direitos. Mesmo trazendo visões distintas do idoso, as narrativas sensibilizam para o cuidado com os mais velhos e alertam para a importância da convivência com a criança.

Palavras-chave: Verbo-visual. PNBE 2010. Velhice. Leitura escolarizada.

Abstract: The production of books for children has been gaining more and more ground in the publishing business, calling attention to challenges and possibilities for the construction of childhood in contemporary times. Therefore, themes that in the past were silenced by the genre, such as old age, are being introduced in literary works aimed at children. This article examines the dialogue between old age and childhood, from the perspective of the relationship between elderly and young fictional characters. To that end, the books De carta em carta, by Ana Maria Machado (2009), and Guilherme Augusto Araújo Fernandes, by Men Fox (1995), both part of the selection of the Brazilian School Library Program (PNBE) for elementary education (2010), are analyzed in relation to their treatment of old age. The investigation is based on the description and analysis of the plots, constructed by means of verbal and visual language, and on the theories of D’Onófrio (2004) and Dondis (2007), who research, respectively, narrative and visual aspects of fiction. The conclusion is that the works analyzed portray social problems experienced by old people in contemporaneity, such as their abandonment in nursing homes and the bureaucratic difficulties they face to have their rights recognized. Showing elderly people from different viewpoints, the narratives 
sensitize the reader regarding the care for senior citizens and call attention to the importance of the co-existence of old and young.

Keywords: Verbal and visual language. 2010 School Library Program. Old age. School reading.

São muitas as tentativas de inserir a literatura na sala de aula e uma das estratégias é a eleição de um tema e a partir dele escolher textos que contemplem diversos modos de representá-lo. Este artigo, ao focalizar duas formas de representar o idoso e a criança em obras destinadas a estudantes dos anos iniciais do Ensino Fundamental, sugere uma alternativa temática de a ficção estar presente nas discussões realizadas nos anos iniciais do Ensino Fundamental.

Questões relacionadas ao idoso e à criança estão sendo cada vez mais discutidas na mídia em geral e nas artes, em virtude da importância atribuída a essas fases da vida. Pesquisas apontam, por exemplo, que, no Brasil, em 1980, a estimativa era de 10 idosos para cada 100 jovens, já em 2050 será de 172 idosos para 100 jovens (BRASIL, 2013a). Implicações na pirâmide estrutural do Brasil levam a crer que se torna necessária uma educação a respeito do idoso nas escolas, e a literatura infantil pode auxiliar, já que, pela leitura da ficção, o leitor experimenta e vivencia atitudes que vão além de sua realidade imediata. A literatura, de acordo com Candido (1995), configura-se como um sonho acordado - assim como não é possível o equilíbrio psíquico sem o sonho durante o sono, talvez não haja equilíbrio social sem a literatura. Desse modo, ela é um fator indispensável para a humanização, porque também atua no inconsciente e subconsciente. Ela tem importância equivalente a outras formas de educação, tais como a familiar, grupal ou escolar (CANDIDO, 1995, p. 243).

Ciente da importância da literatura para a formação humana, o PNBE, criado pelo Governo Federal, em 1997, incentiva a leitura de alunos e professores por meio de acervos literários, alocados nas bibliotecas escolares. Atualmente, o Programa abrange todas as escolas públicas do País desde a Educação Infantil, contemplando crianças de zero a três anos, até as classes de Ensino Médio e Educação de Jovens e Adultos. Este estudo - pertencente ao projeto "Desafios e acolhimentos da literatura infantil: a mediação de leitura literária”, aprovado pela FAPERGS e realizado na UCS - tem como objetivo discutir o modo como as obras De carta em carta, escrita por Ana Maria Machado e ilustrada por Nelson Cruz (2009), e Guilherme Augusto Araújo Fernandes, escrito por Men Fox e ilustrado por Julie Vivas (1995), apresentam o velho interagindo com a criança. O artigo defende a presença de tais títulos em sala de aula, como estratégia para sensibilizar o estudante sobre o respeito, cuidado e afeto com o idoso e ainda os modos de a criança relacionar-se com os mais velhos.

Entende-se que o objeto livro, manuseado pelo leitor, é um produto híbrido e assim procede-se à interação, ou seja, o livro literário destinado 
à infância é formado por linguagem verbal e visual e tais linguagens interagem com o leitor no processo de significação do título (RAMOS; PANOZZO, 2011).

\section{Construção de identidades na infância e na velhice}

De carta em carta apresenta-se ao leitor por meio de um exemplar com 20,5 x 26,6 cm de dimensões, 32 páginas numeradas, confeccionado com papel resistente na capa e gramatura média no miolo, facilitando o manuseio do público infantil. A ilustração é elaborada com traços imprecisos, dado que sugere identificação com o leitor que nesta fase ainda não conta com a precisão da coordenação motora fina.

A capa ${ }^{1}$ é colorida em tons sombrios, predominando tonalidades que vão do verde ao acinzentado (Figura 1). A imagem representa uma praça que conta com um local coberto, no canto direito algumas pessoas estão sentadas lendo ou escrevendo para outras, no meio, há um menino que recebe uma carta. Ela antecipa personagens da história, como o protagonista, Pepe, ilustrado na área central, que mais tarde será apresentado como um frequentador do local. As personagens ilustradas no canto direito escreviam cartas para aqueles que não tinham essa habilidade. A alternância de sombra e luz ilumina o protagonista, enquanto personagens secundários trabalhadores e outros fregueses - ficam mais apagados.

Figura 1 - Capa do livro De carta em carta

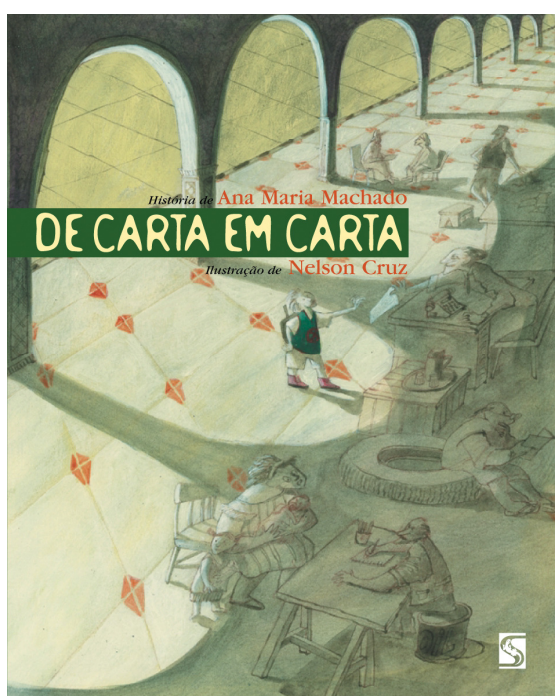

Fonte: MACHADO, Ana Maria. De carta em carta. Il. Nelson Cruz. São Paulo: Salamandra, 2009.
A narrativa verbal inicia situando o leitor no tempo e no espaço. Aliás, a caracterização do cenário ocorre também pela ilustração do ambiente. Em seguida, a palavra configura Pepe como um menino não muito pequeno, mas que ainda não sabia ler nem escrever. Morava com sua família, o pai, a mãe, quatro irmãos e o avô. Todos os dias os pais saiam para o trabalho e os irmãos para a escola. Pepe preferia ficar em casa brincando e, às vezes, ajudando o avô. Na abertura da narrativa, o texto assume uma proposta estática, sem movimentação da história (D’ONÓFRIO, 2004, p. 77).

Aos poucos, o conflito vai sendo posto: um dia, avô e neto saem para trabalhar. Eles acabam se desentendendo, a ponto de o avô
${ }^{1}$ Entende-se que a capa atua como porta de entrada para o leitor interagir com o texto literário. Mais dados acerca dessa concepção podem ser obtidos no artigo "Acesso à embalagem do livro infantil” (RAMOS; PANOZZO, 2005). 
proibir Pepe de falar e teimar. A ilustração ajuda na significação desse momento, quando o avô aponta para o menino ir ao castigo e Pepe aparece com os braços cruzados, não aceitando as ordens. O menino, então, volta para casa e, no caminho, encontra a Praça dos escrevedores, quando tem a ideia de mandar uma carta para o avô. No local, conhece seu Miguel, um escrevedor, mas não tem dinheiro para lhe pagar a escrita da carta. $\mathrm{O}$ trabalhador faz uma proposta para que o menino lhe pague indo à escola e, no dia seguinte, lhe conte o que acontecera. Pepe pede que Miguel escreva: “Você está tão chato... Vá para o inferno!” Depois de assinar e colocar o nome de seu avô, vai entregar.

No dia seguinte, antes de sair para a escola, o menino entrega a carta. Mais tarde, seu José, o avô, vai até a praça para que alguém leia a carta para ele. Encontra, então, Seu Miguel, que não se sente à vontade para ler o que estava escrito a um senhor daquela idade e lê: "Você está cansado. Vá para o inverno! Pepe.” Nesse momento, há um jogo de palavras usado através da rima para brincar com o leitor. As palavras chato/cansado e inferno/inverno são trocadas e mudam o sentido da mensagem redigida pelo menino. $\mathrm{O}$ avô pensa um pouco, não sabe o que responder e decide falar da família. Agradece pela lembrança e comenta que o neto se importa com seu estado, aconselhando-o a ir para o inverno. Entretanto, não perde a oportunidade de chamá-lo de atrevido e malcriado.

Mais tarde, Pepe chega até a praça para contar como foi seu dia de aula e pagar a dívida. No dia seguinte, recebe a carta do avô e vai até o seu Miguel pedir que a leia. Dessa vez, o texto não é alterado na leitura. Pepe responde a carta, dizendo que o avô é um velho maluco, mas acrescenta “atenciosamente, seu neto”. Seu Miguel escreve e, por solicitação de Pepe, lê o escrito. O menino não aceita o registro e solicita que seja escrito apenas o que ele disse, e Miguel cumpre a determinação.

Passa-se um dia, o menino recebe a carta com a resposta do avô e vai novamente à praça para que Miguel a leia. Dessa vez, não quer responder; reaparece no dia seguinte, pedindo ao escrivão que redija uma carta ao Governo, reivindicando a aposentaria do avô. Semanas depois, Seu José recebe uma carta, notificando-o de que teria direito a receber seu benefício e, portanto, não precisa mais trabalhar.

Pepe aprende a ler e ajuda seus amigos escrevendo cartas, cresce e continua estudando por muito tempo até que vai trabalhar junto a um posto de atendimento governamental, ajudando pessoas que precisam de aposentadoria. A ilustração final exibe Pepe no trabalho, conversando com uma senhora e algumas cartas em cima da mesa - o menino agora é adulto, está feliz, demonstrado pelo sorriso no resto. A última página, semelhante à primeira, traz a imagem de entrada, que poderia ser a saída, indicando ao leitor uma despedida da história. Assim como o momento inicial, o final 
também é estático, já que o conflito posto foi solucionado, retornando a uma situação de equilíbrio (D’ONÓFRIO, 2004, p. 85).

"Era uma vez” alerta para a imprecisão da narrativa ao mesmo tempo em que estende o conflito proposto a diversas situações. Os fatos ocorrem sequencialmente e respeitam a cronologia, até que há um deslocamento temporal da infância para a fase adulta de Pepe, quando ele já trabalha. Para marcar a transição temporal, o narrador alerta: "Passou-se o tempo. Os dias viraram semanas, as semanas viraram meses, os meses viraram anos.” (MACHADO, 2009, p. 31).

Conforme D’Onófrio (2004), a temporalidade é um componente sintático-semântico da narrativa que apresenta as relações entre passado, presente e futuro. A ficção literária é uma arte temporal, e toda diegese pressupõe início, meio e fim (2004, p. 99). A cronologia é respeitada, coerente ao modo como o leitor mirim processa o seu entorno.

Já a espacialidade, mesmo trazendo espaços citadinos, contribui para dar ambientar o conflito e instaurar o mundo imaginário, suspendendo as leis do real (D’ONOFRIO, 2004, p. 96). No enredo, a espacialidade configura o cenário de uma cidade:

A cidade era antiga e ficava à beira do mar. Tinha ruas estreitas, igrejas lindas e pracinhas. Tinha lembranças de um tempo de muita riqueza. Tinha fortes que não serviam para mais nada, mas antigamente tinham sido usados para defender a cidade dos ataques piratas. Tinha casas coloniais de dois andares, com jardins em pátios internos e varandinhas cheias de vasos de flores. E em alguns lugares, essas varandas eram grandes, no segundo andar, por cima de uns arcos que se apoiavam nas calçadas em volta das praças e largos. (MACHADO, 2009, p. 4).

O conflito materializa-se pela ilustração e pela palavra. Visualmente, prevalecem cores opacas, acinzentadas e envelhecidas, enfatizando que o tempo narrado está distante do leitor. Na área central está a praça, reiterada pela ilustração como espaço privilegiado, descrita verbalmente apenas na página seguinte, de modo que a ilustração antecipa sentidos ainda não trazidos pela palavra. No alto da imagem, estão os tons fortes, em traços leves e esboçados, expressando sentimento de algo que já não é mais importante. Logo abaixo da imagem, uma mãe caminha com sua filha sob um guarda-sol colorido, mobilizando o olhar do leitor pelas cores verde, vermelho, amarelo, azul.

Após situar a cidade, o narrador privilegia a praça, espaço central da trama. Em seguida, focaliza dois fregueses e o local onde moram e trabalham. Ao final, acrescenta o espaço onde fica "o pessoal que cuida dos aposentados”, ou seja, o instituto previdenciário, órgão para o qual Pepe escreveu uma carta reivindicando a aposentadoria de seu avô. 
Esses espaços também podem ser analisados de acordo com a ilustração. O posto de atendimento do governo é edificado por cores frias e envelhecidas, representando locais antigos (Figuras 2 e 3). Na primeira ilustração, a atenção do leitor é atraída por uma cadeira vermelha e um toque de luz ilumina um senhor que lê a carta enviada por Pepe com o auxílio de óculos e lupa, demonstrando dificuldade de visão. Mais tarde, quando o menino já está adulto, o local reaparece sobre o mesmo fundo, sugerindo que ali nada mudou. Algumas gavetas do armário de pastas suspensas estão entreabertas, Pepe e uma senhora conversam. Entre a imagem dos personagens e o armário na parede, há uma mesa com alimentos, juntamente com alguns papéis, prováveis documentos da repartição.

De carta em carta é escrito por narrador pressuposto (D’ONÓFRIO, 2009, p. 59), não fazendo referência explícita ao narrador e ao destinatário. O registro em terceira pessoa transmite substância factual com distanciamento. Trata-se de narrador onisciente seletivo, ou seja, o narrador apresenta o ponto de vista de uma ou mais personagens, no momento presente, pela voz de uma personagem. O narrador atua como transmissor e intérprete da visão de mundo do protagonista e informa ao leitor o estado de humor de cada personagem como se estivesse acompanhando-o.

Pepe, o protagonista, é descrito como um menino "não tão pequeno assim, mas ainda não sabia ler nem escrever” (MACHADO, 2009, p. 4). Ele não gosta de ir à escola e, então, fica em casa ajudando o avô, até que se vê obrigado a frequentá-la para pagar uma dívida. Quando termina o pagamento, o menino continua indo ao colégio, pois gosta do que aprende. Quando já lê e escreve, ajuda o avô a conseguir a aposentadoria e também vários amigos que precisam escrever. Ao se tornar adulto, passa a auxiliar pessoas que precisam de aposentadoria.

Figuras 2 e 3 - O repouso dos processos: entre sombra e luz

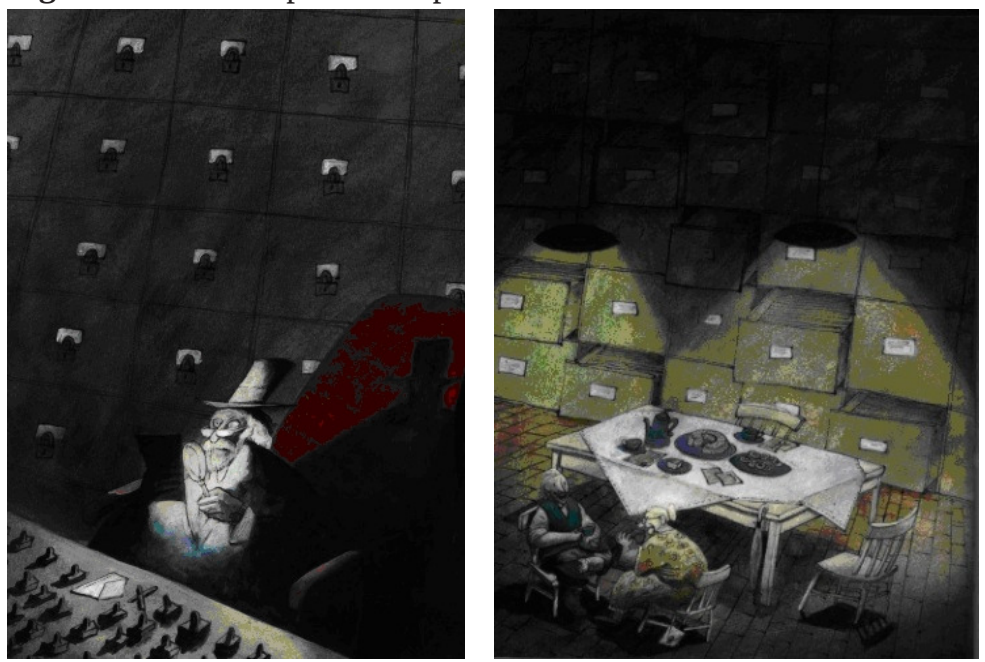

Fonte: MACHADO, Ana Maria. De carta em carta. Il. Nelson Cruz. São Paulo: Salamandra, 2009, p. 28 e 30. 
Seu José é um senhor com idade avançada que mora com a filha e os netos. Não conta com o auxílio de aposentadoria e, por isso, precisa fazer alguns trabalhos de jardinagem pela vizinhança. Miguel é um trabalhador da Praça dos escrevedores; cobra, conforme o tamanho da carta. Quando conhece Pepe, sente-se triste por saber que um menino tão jovem não vai à escola. Não cobra as cartas que escreve para o menino, mas, como forma de pagamento, pede-lhe que vá à escola e lhe conte como é lá.

Na primeira vez em que o escrevedor faz uma carta a pedido de Pepe, coloca tudo o que o menino solicita, porém quando lê para o avô, coloca seus sentimentos acima da palavra grafada. Acha que o senhor não merece escutar aquilo e diz-lhe palavras parecidas, que rimam, mas que têm significado diferente. Além de contribuir para aproximar avô e neto, Miguel também conduz Pepe à escola.

Os pais de Pepe não interferem imediatamente na situação entre avô e neto. Os dois saíam para trabalhar, e as responsabilidades de cuidado eram transferidas ao seu José.

Todo dia, bem cedo, o pai e a mãe saíam para trabalhar. Os irmãos mais velhos saíam para a escola. Pepe ficava com o avô. Já tinha idade para ir ao colégio, mas não queria. Preferia ficar brincando e quase sempre faltava à aula. Dizia que precisava fazer companhia ao velho e os pais acabavam deixando. (MACHADO, 2009, p. 7).

É possível perceber através dessas informações que os pais de Pepe deixam-se enganar pelas desculpas do menino, acreditando apenas na importância de alguém acompanhar o idoso.

A narrativa alerta para muitos pontos, como a importância da escolarização, o cuidado com o idoso, as relações entre neto e avô, o papel ativo que pode ser assumido pela criança. Tais sentidos podem ser trazidos para a escola e problematizados a partir da leitura da narrativa. Essas questões, como já apontado, originam-se da articulação entre a palavra e a ilustração.

\section{Memória na velhice e na infância}

Guilherme Augusto Araújo Fernandes foi publicado originalmente na Austrália, em 1984, e traduzido para o português em 1995. Possui 24 x 25,5 cm, 32 páginas numeradas, dimensões apropriadas para o público infantil, permitindo ao leitor facilidade no manuseio. O livro tem como plano de fundo o branco, e na área central de cada página, tons bastante coloridos e quentes, de modo que a visualidade auxilia o leitor mirim a significar a narrativa verbal. A capa (Figura 4) antecipa a presença de dois personagens, que mais tarde são conhecidos como Guilherme, nome que dá título ao exemplar, e Dona Antônia, a idosa que perdeu a memória. 
Figura 4 - Capa de Guilherme Augusto Araújo Fernandes

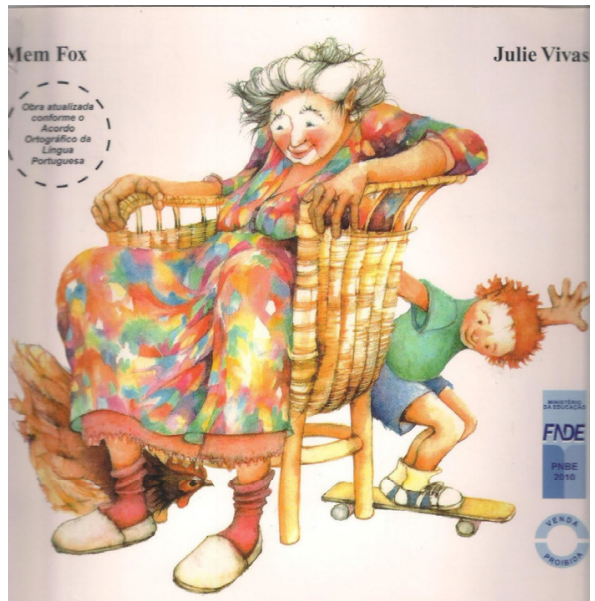

Guilherme Augusto Araújo Fernandes sannoue-book

Fonte: FOX, Mem. Guilherme Augusto Araújo Fernandes.Il. Julie Vivas. Trad. Gilda Aquino. São Paulo: BrinqueBook, 1995.
Na capa, topologicamente, há uma situação de equilíbrio: a idosa se localiza no meio, o menino, no lado direito, e o galo, à esquerda, atrás da perna de dona Antônia. O nome do livro, situado horizontalmente na parte inferior, atua como base para a imagem central. Para Dondis (2007, p. 32), o equilíbrio é a referência visual mais forte e firme ao ser humano, com base consciente e inconsciente para fazer avaliações visuais. Existe um processo de ajustamento a cada variação de peso pela reação de contrapeso, já que o equilíbrio é fundamental na natureza e no homem. Nesse caso, o processo de estabilização, enunciado pela disposição dos elementos visuais encontra apoio na figura do menino, que se equilibra em cima de skate.

Ao abrir o livro, o leitor depara-se com a imagem de dona Antônia, agora sentada de costas para o leitor, na mesma cadeira de palha mostrada na capa, apenas em outro ângulo, como se estivesse dando as costas à vida anterior, ao momento da narrativa. No par de páginas seguinte, há seis cadeiras, três em cada um, das quais cinco estão ocupadas por idosos, que novamente se colocam de costas para o público. A última está vazia, dando espaço à imaginação de quem lê. Nas páginas 12 e 13, há outro par de imagens com cadeiras dispostas, como anteriormente, mas, desta vez, estão de frente e, em uma delas, quem está sentado é Guilherme, que, por ser pequeno, acaba se escondendo no assento.

As cores ajudam na significação do contexto e estão diretamente ligadas a emoções, de modo que cada uma pode assumir um significado associativo e simbólico. As ilustrações deste exemplar mesclam tons rochosos com outras tonalidades, revelando uma indefinição cromática que mimetiza o estado emocional de dona Antônia.

O narrador em terceira pessoa apresenta o protagonista e o espaço onde acontece o enredo:

Era uma vez um menino chamado Guilherme Augusto Araújo Fernandes

E ele nem era tão velho assim. 
Sua casa era ao lado de um asilo de velhos.

E ele conhecia todo mundo que vivia lá. (FOX, 1995, p. 5).

Guilherme morava ao lado de um asilo e era conhecido por todos os idosos que ali residiam. O tempo da história é impreciso, mas o enredo situa-se no passado, não sendo possível precisar quando aconteceu. No decorrer do conflito, alguns moradores do asilo são mostrados pela visão de Guilherme, que os caracteriza. A pessoa de que o menino mais gostava era a Sra. Antônia Maria Diniz Cordeiro, a quem contava todos os seus segredos. Aqui, há uma ruptura no estado inicial da narrativa, quando predomina a descrição dos personagens. Esse modo de narrar é peculiar a essa modalidade textual, já que, mesmo a situação inicial sendo estática já anuncia o conflito.

Não há demarcação temporal, posto que o "Era uma vez” não informa quando os fatos aconteceram. No primeiro momento, o narrador apresenta os personagens do enredo. Ao terminar a descrição do momento inicial, surge a primeira transformação (com a notícia da perda da memória da dona Antônia), delimitada pela expressão “Um dia”. A partir desse momento, o restante da história passa-se no mesmo dia, pois não há notificação de mudança temporal.

O enredo ocorre em dois espaços: na casa de Guilherme e no asilo (Figuras 5 e 6). O primeiro é situado na abertura da narrativa, acompanhado pela ilustração. No fundo da imagem, há uma moradia, mais à frente, algumas roupas estendidas e, sobre o chão, vários brinquedos espalhados. As cores sinalizam um ambiente tranquilo. Uma cerca divide o par de páginas que forma o todo da ilustração. Na outra parte, há o segundo espaço: o asilo, também ilustrado com a moradia ao fundo da imagem e os idosos à frente da casa.

Figuras 5 e 6 - Cenário de abertura da narrativa

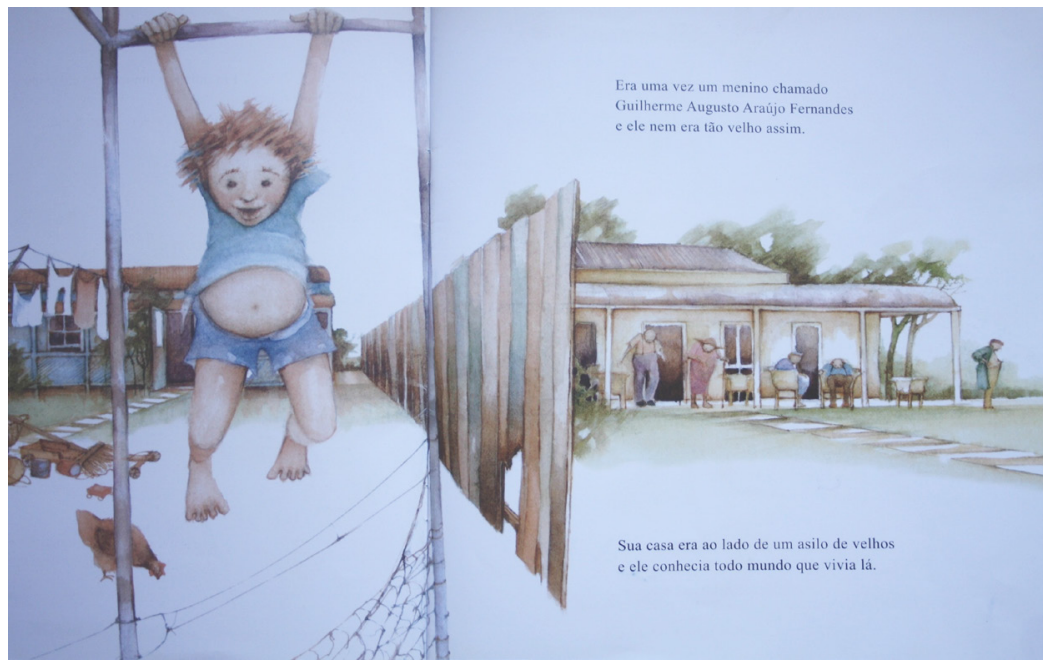

Fonte: FOX, Mem. Guilherme Augusto Araújo Fernandes.Il. Julie Vivas. Trad. Gilda Aquino. São Paulo: Brinque-Book, 1995. 
As linguagens verbal e visual conversam entre si, fornecendo elementos necessários para a concretização do leitor sobre espacialidade. Enquanto a visualidade mostra o mundo de Guilherme, brinquedos no pátio, felicidade representada no sorriso e o repouso dos idosos, a narrativa verbal apenas descreve os espaços e a ligação que há entre eles: "Sua casa era ao lado de um asilo de velhos e ele conhecia todo mundo que vivia lá.” (p. 5). Para o leitor, a visualidade aproxima-o do cenário.

Ao ouvir seus pais dialogarem sobre a perda da memória de sua amiga, o menino ficou curioso sobre o significado da palavra "memória” e indagou ao pai, que lhe respondeu: “É algo que você se lembre”. Mas Guilherme queria saber mais acerca do termo. O conflito se desenrola a partir da curiosidade de Guilherme sobre o sentido de “memória”. Insatisfeito com a resposta do pai, pergunta aos amigos do asilo acerca do vocábulo e obtém as seguintes respostas:

[...] Algo quente, meu filho, algo quente.

[...] algo bem antigo, meu caro, algo bem antigo.

[...] Algo que faz chorar, meu menino, algo que faz chorar.

[...] Algo que faz rir, meu querido, algo que faz rir.

[...]Algo que vale ouro, meu jovem, algo que vale ouro. (FOX, 1995, p. 11 a 16).

Esse momento pode ser caracterizado como a primeira transformação, que só acontece quando o sujeito sai do estado de inércia. Assim, o não saber do menino é mote para que a história aconteça, e a narrativa constitui-se por uma sequência de situações determinadas pela transformação sofrida pelo fazer dos personagens (D’ONÓFRIO, 2004, p. 77). A curiosidade acerca da memória perdida da Dona Antônia faz com que o protagonista se afaste de sua rotina em busca de respostas. Guilherme voltou para casa - espaço conhecido - e procurou objetos que pudessem ser a memória de dona Antônia, de acordo com a aprendizagem feita com os idosos: algo quente, algo que fizesse rir, algo que fizesse chorar... Juntou elementos com tais características e levou-os até Dona Antônia que, pela materialidade, recuperou sua memória.

Nesse momento do enredo, há uma força equilibrante que repara o conflito anterior. Como Dona Antônia havia perdido sua memória, o protagonista resolve a situação a partir de seu conhecimento, valendo-se de sua memória. O menino e a senhora voltaram a sorrir, pois, Gabriel constituiu um entendimento acerca do que é memória e ainda ajudou a idosa a restaurar a sua, que havia sido perdida. Nessa situação, o equilíbrio prevalece no final do enredo.

O protagonista procurou tudo o que acreditava concretizar o conceito aprendido - um ovo ainda quente, uma caixa de conchas que havia guardado há muito tempo, uma medalha que, com tristeza, lembrava seu 
avô, uma marionete que fazia todo mundo rir e uma bola que, para ele, valia ouro - e levou para Dona Antônia.

O imaginário infantil rompe com certezas do mundo adulto. Guilherme, que ainda não tinha um conceito elaborado acerca do significado de memória, estabeleceu alguns nexos que deram sentido à palavra. O personagem recorreu a materiais concretos, assim como uma criança que está no período pré-operatório, que abrange, conforme Piaget (1986), crianças de dois a sete anos. Esse momento é caracterizado pela dificuldade de abstração, e a criança não aceita a ideia do acaso, de modo que tudo precisa de uma explicação. Assim, para o menino, a memória precisava ser algo visível e palpável, para que tivesse sentido. Para o público leitor, o enredo possibilita a identificação com o personagem, uma vez que revela o percurso que a criança realizou para entender um vocábulo desconhecido.

A criança é ativa e auxilia Dona Antônia - a senhora mais próxima do protagonista, que ouve seus segredos e histórias. Quando o menino mostra objetos que lhe fazem sentido, dona Antônia começa a relembrar algumas vivências esquecidas: com uma das conchas no ouvido, lembrou-se de quando fora à praia de bonde; quando segurou um ovinho, lembrou que havia pintado um de azul quando era pequena e assim por diante, até chegar a memória mais recente de quando jogou com uma bola de futebol, recordando-se de quando conheceu o menino Guilherme. Enfim, pela interação entre criança e idoso dão sentido às suas vidas.

\section{Apontamentos para o ensino da leitura na escola}

A escolha desses dois livros para este artigo deu-se porque há um tema em comum: a velhice. Em De carta em carta há o retrato do idoso dependente do trabalho informal, em Guilherme Augusto Araújo Fernandes, os idosos estão asilados. As obras trazem um tema atual e relevante no cenário mundial, mas tratado literariamente, ou seja, sem postura doutrinária, que direcione o comportamento do leitor.

O idoso tem um papel muito relevante na sociedade. Conforme Bosi (1994), é fonte de cultura que conserva o passado e prepara o presente. Os velhos são os guardiões do passado e nós deve-se lutar por eles, já que a cultura trata a velhice como oprimida, despojada e banida. O idoso lembra e aconselha, une o fim ao começo, ligando o que foi ao por vir. Em geral, nossa sociedade bloqueia lembranças e recusa conselhos, destrói a memória e a substitui pela história oficial celebrada.

O PNBE 2010 traz nos dois livros analisados, além da preocupação com o idoso, a promoção dessa etapa da vida por meio do discurso ficcional. A literatura cria mundos possíveis que contribuem para o alargamento das experiências dos leitores. 
A leitura tem mais chances de se efetivar quando há alguma ligação entre o leitor e o texto e, nessas obras, os protagonistas são crianças, assim como o provável estudante que vai manuseá-las. Muitas, entretanto, são as obras que têm como protagonista um ser com idade e interesses similares aos prováveis receptores, mas isso não basta para que a leitura cumpra seu papel de propiciar uma experiência estética. A linguagem precisa mobilizar o leitor de modo que atue como coautor do texto.

Os conflitos postos nas narrativas selecionadas unem dois pontos da vida - a infância e a velhice, contribuindo para que o leitor mirim entenda acerca das relações humanas, da passagem do tempo e do envelhecimento. A presença do idoso em obras do PNBE 2010 propõe uma reflexão acerca do lugar social do idoso. José, do livro De Carta em Carta, apesar da idade, trabalha e cuida dos netos, não é alfabetizado, sendo retratado como incapaz de viabilizar sua aposentadoria. O neto, a criança, essa fonte de transformação, contribui para alterar a condição de vida do avô, pois sua situação muda quando Pepe escreve uma carta aos postos do governo, denunciando a situação do avô.

O acervo contempla também outra condição do idoso e traz a situação daquele asilado e que não tem mais memória, como é o caso de dona Antônia. Em Guilherme Augusto Araújo Fernandes, vários idosos passam os dias rememorando suas memórias, como se viver fosse apenas rememorar o passado. O menino que mora ao lado, escuta-os e sua ação ajuda dona Antônia a recuperar, metaforicamente, algumas lembranças. Enfim, nas duas obras, as crianças interferem na ação posta e contribuem para que os idosos tenham mais qualidade de vida por meio de atitudes singelas.

Outro ponto a destacar nas obras é o modo como as histórias vão sendo apresentadas ao leitor por meio de texto verbal e visual, que se unem sincreticamente e, ao mesmo tempo, contribuem para a concretização das linguagens, desafiando o leitor a associar elementos postos pelas duas linguagens. Ler narrativa verbo-visual implica interagir com elementos dos dois códigos, já que a ilustração não exerce função meramente decorativa, ao fazer parte da significação da obra.

\section{Referências}

BOSI, Ecléa. Memória e sociedade: lembranças dos velhos. 3. ed. São Paulo: Companhia das letras, 1994.

BRASIL. Portal da Saúde. Brasil terá 63 milhões de idosos em 2050. Disponível em: <http://portal.saude.gov.br/portal/saude/visualizar_texto. cfm?idtxt=34054\&janela=1 > acessado em 15 de julho de 2013a.

BRASIL. Ministério da educação. Programa Nacional Biblioteca da Escola. Disponível em: $<$ http://portal.mec.gov.br/index.php?option=com_conte nt\&view=article\&id=12368\&Itemid=574> acessado em 15 de julho de 2013b. 
CÂNDIDO, Antônio. Vários escritos. 3. ed. rev. e ampl. São Paulo: Duas Cidades, 1995.

DONDIS, Donis A. Sintaxe da linguagem visual. Tradução Jefferson Luiz Camargo. $3^{\circ}$ ed. São Paulo: Martins Fontes, 2007.

D’ONOFRIO, Salvatore. Teoria do texto. 2. ed. São Paulo: Ática, 2004.

FOX, Mem. Guilherme Augusto Araújo Fernandes. Ilustrado por Julie Vivas; tradução de Gilda Aquino. São Paulo: Brinque-Book, 1995.

MACHADO, Ana Maria. De carta em carta. Ilustração de Nelson Cruz. São Paulo: Salamandra, 2009.

PIAGET, Jean. A linguagem e o pensamento da criança. 4. ed. rev. São Paulo: M. Fontes, 1986. 212 p.

RAMOS; Flávia B.; PANOZZO, Neiva S. P. Interação e mediação de leitura literária para a infância. São Paulo: Global, 2011.

Acesso à embalagem do livro infantil. PERSPECTIVA, Florianópolis, v. 23, n. 01, p. 115-130, jan./jul. 2005. Disponível em https://periodicos.ufsc.br/index.php/perspectiva/article/view/9734/8962. Acesso em 6 fev 2014.

Recebido em 18/11/2013

Aprovado em 5/2/2014 